\title{
High-Dose Paraquat Induces Human Bronchial 16HBE Cell Death and Aggravates Acute Lung Intoxication in Mice by Regulating Keap1/p65/Nrf2 Signal Pathway
}

\author{
Jiexiong Yao, ${ }^{1}$ Jihua Zhang, ${ }^{2}$ Wenlin Tai, ${ }^{3}$ Shuhao Deng, ${ }^{4}$ Ting $\mathrm{Li}^{4}{ }^{4}$ Wenjuan $\mathrm{Wu}^{4}{ }^{4} \mathrm{Lin} \mathrm{Pu}^{4}$ \\ Du Fan, ${ }^{4}$ Wen Lei, ${ }^{4}$ Tao Zhang, ${ }^{4}$ and Zhaoxing Dong ${ }^{4,5}$
}

\begin{abstract}
Paraquat (PQ) intoxication seriously endangers human beings' health, however, the underlying mechanisms are still unclear. Here we found that PQ inhibits human bronchial 16HBE cell proliferation and promotes cell apoptosis, necrosis as well as ROS generation in a dose dependent manner. Of note, low-dose PQ $(50 \mu \mathrm{M})$ induces cell autophagy, increases Nrf2 as well as p65 levels and has little impacts on Keap1, while high-dose PQ $(500 \mu \mathrm{M})$ inhibits autophagy, upregulates Keap1 as well as downregulates p65 and Nrf2. In addition, we verified that p65 overexpression increases Nrf2 and its downstream targets in 16HBE cells, which are reversed by synergistically knocking down Nrf2. Our further results showed that high-dose PQ's effects on cell proliferation, apoptosis, ROS levels and autophagy are reversed by p65 overexpression. Besides, the protective effects of overexpressed p65 on high-dose PQ $(500 \mu \mathrm{M})$ treated 16HBE cells are abrogated by synergistically knocking down Nrf2. In vivo experiments also showed that high-dose PQ promotes inflammatory cytokines secretion, lung fibrosis and cell apoptosis, inhibits cell proliferation in mice models by regulating Keap1/p65/Nrf2 signal pathway. Therefore, we concluded that high-dose PQ $(500 \mu \mathrm{M})$ inhibits $16 \mathrm{HBE}$ cell proliferation and autophagy, promotes cell death and mice lung fibrosis by regulating Keap1/p65/Nrf2 signal pathway.
\end{abstract}

KEY WORDS: Paraquat; Lung fibrosis; Keap1; Nrf2; p65.

Jiexiong Yao, Jihua Zhang, Wenlin Tai and Shuhao Deng contributed equally to this work.

\footnotetext{
${ }^{1}$ Department of Internal Medicine Ward 5, Guangdong Provincial Corps Hospital of Chinese People's Armed Police Forces, Guangzhou Medical University, Guangzhou, Guangdong 510507, People's Republic of China

${ }^{2}$ Department of Pulmonary and Critical Care Medicine, The People Hospital of Yuxi City, Yuxi, China

${ }^{3}$ Department of Clinical Laboratory, Yunnan Molecular Diagnostic Center, The 2nd Affiliated Hospital of Kunming Medical University, Dianmian Road, Kunming, Yunnan, China

${ }^{4}$ Department of Respiratory, The 2nd Affiliated Hospital of Kunming Medical University, Dianmian Road 374, Kunming, 650101, Yunnan, China

${ }^{5}$ To whom correspondence should be addressed at Department of Respiratory, The 2nd Affiliated Hospital of Kunming Medical University, Dianmian Road 374, Kunming, 650101, Yunnan, China. E-mail: zhangtao08265@163.com
}

\section{INTRODUCTION}

Paraquat (PQ) is one of the most common herbicides worldwide which is especially used in developing countries. PQ poisoning seriously endangered human being's health, although it has been banned in most countries, it remains a commonly used agent causing death from self-poisoning with herbicide in developing countries $[1,2]$. It has been reported that PQ poisoning causes human death by regulating DNA breakage [3], mitochondrial damage [4], cell apoptosis [5], and cell autophagy [6], but the detailed mechanisms of PQcaused human death are still not fully delineated. Studies proved that accumulated PQ in lung tissues induces 
ROS generation [7] as well as inflammatory reactions [8], both of which play important roles in regulating lung fibrosis. The studies above indicated that ROS generation and inflammatory reactions might serve as therapeutic targets for PQ poisoning.

Recent study found that PQ treatment inhibits the viability of human neural progenitor cells by promoting ROS generation [9]. Besides, PQ induces hepatic injury in mice [10] and promotes mouse alveolar type II cell apoptosis by promoting ROS production. In addition to apoptosis, PQ promotes cell intoxication by regulating cell autophagy [11]. Autophagy has opposite effects on cells' responses to environmental stress; on the one hand, autophagy prevents cells from apoptosis under environmental stresses [12]. On the other hand, autophagy-induced cell death has also been reported [11]. However, the role of autophagy in PQ-induced cell intoxication is still unclear. Of note, targeting paraquat-induced ROS generation has proved to be effective for the attenuation of lung fibrosis [13]. Furthermore, PQ-induced lung fibrosis is also closely related with inflammatory reactions, and anti-inflammatory agents have been reported to alleviate PQ-induced pulmonary injury in mice [14]. Therefore, PQ-induced ROS generation, cell autophagy, apoptosis, and inflammatory reactions might be pivotal for the pathogenesis of PQ-induced lung fibrosis, but the detailed mechanisms still need to be explored.

Kelch-like ECH-associated protein 1(Keap1)/p65/ nuclear factor E2-related factor 2 (Nrf2) signal pathway is closely related with ROS generation. In normal cells, Keap1 binds to Nrf2 and activates its degradation processes [15]. However, Nrf2 is released from Keap1Nrf2 complexes under the conditions with high ROS levels. Nrf2 binds to antioxidant response elements (AREs) in the nucleus and promotes the transcription of a wide variety of antioxidant genes, which helps to eliminate ROS levels and protect cells from ROSinduced cell death [16]. Keap1 physically associates with p65 [17], but it is still unclear whether p65 involves in the activation of Keap1/Nrf2 signal pathway. The activation of Keap1/Nrf2 signal pathway is also reported to regulate ROS-regulated cell autophagy [12] and apoptosis [18]. In addition, Nrf2 has also been reported to modulate inflammatory reactions [19].

Taken together, we hypothesized that PQ might induce ROS generation, cell apoptosis. and lung fibrosis by regulating Keap1/p65/Nrf2 signal pathway, and uncovering the underlying mechanisms might shed light on the discovery of therapeutic agents for PQ intoxication.

\section{MATERIALS AND METHODS}

\section{Animals}

Seven to 8 weeks male C57BL/6 mice (the total number was 20 and the weight of the mice ranged from 20 to $25 \mathrm{~g}$ ) were purchased from Vital River Laboratory Animal Technology (Beijing, People's Republic of China). All animal care and handling procedures were in accordance with the guidelines of the Institute for Laboratory Animal Research of the Second Affiliated Hospital of Kunming Medical University. The animal for research use was approved by the Animal Care and Use Committee of the Second Affiliated Hospital of Kunming Medical University. The animals were fed and maintained under the same conditions (temperature $23 \pm 2{ }^{\circ} \mathrm{C}$, humidity $55 \pm$ $5 \%, 12: 12 \mathrm{~h} \mathrm{light/dark}$ cycle) in the Animal Research Center of Kunming Medical University. The mice were selected and divided into four groups and administered with $500 \mu \mathrm{M}$ of PQ (Sigma-Aldrich, St. Louis, MO, USA) or the same volume of saline (control) by intraperitoneal injections. After $96 \mathrm{~h}$, mice were sacrificed and the samples of lung tissues and peripheral blood were collected for the following studies.

\section{Detection of Tissue Morphology by Masson Staining}

The Masson Staining Kit was purchased from Shanghai Bogoo Biotechnology Co., Ltd. (China). Mice lung tissues were collected and fixed in $4 \%$ paraformaldehyde for 24-48 $\mathrm{h}$ and embedded in paraffin wax for long-term preservation. Wax was then cut into $5 \mu \mathrm{M}$ thicknesses. The paraffin-embedded sections were then de-paraffinized by xylene, and a series of ethanol were used to process and dehydrate the sections. The sections were then washed with phosphate buffer solution (PBS) three times, and the tissues were then stained with reagent $\mathrm{A}, \mathrm{B}$, and $\mathrm{C}$ sequentially according to the manufacturer's protocol; optical microscope was used to observe tissue morphologies.

\section{Cell Culture and Cell Proliferation}

$16 \mathrm{HBE}$ cells were diluted into the density of $1 \times 10^{4} /$ $\mathrm{ml}$ and seeded into 96-well plates; cells were then cultured under the standard conditions $\left(37^{\circ} \mathrm{C}, 5 \% \mathrm{CO}_{2}\right)$ for $12 \mathrm{~h}$. Different doses of PQ $(50 \mu \mathrm{M}, 150 \mu \mathrm{M}$, and $500 \mu \mathrm{M})$ were added into the wells (each assay has three repetitions) and co-cultured with cells for $12 \mathrm{~h}, 24 \mathrm{~h}, 48 \mathrm{~h}, 72 \mathrm{~h}$, and $96 \mathrm{~h}$ respectively. Ten microliters of CCK-8 solution was added into each well and incubated in the plate for $1-4 \mathrm{~h}$ in the incubator following the manufacturer's instructions of Cell 
Counting Kit-8 (MedChemExpress Co., Ltd., USA). Before reading the plate, the plate was gently mixed on an orbital shaker for $1 \mathrm{~min}$; the optical density (OD) values were detected by a Gemini EM microplate reader (Molecular Devices, USA) at the absorbance of $450 \mathrm{~nm}$. The OD values were used to evaluate cell proliferative abilities after being treated by different doses of PQ at various time points.

\section{Real-Time qPCR}

After treating 16HBE cells and mice with different doses of PQ, TRIzol kit (Invitrogen, USA) was used to extract RNA from 16HBE cells or mice lung tissues following the manufacturer's protocol. Reverse transcription PCR by iScript cDNA Synthesis Kit (Bio-Rad, Hercules, CA, USA) and real-time quantitative PCR by HiScript II Q Select RT SuperMix (Vazyme, China) were used to reverse and quantify relative GAPDH, Keap1, p65, Nrf2, IL-4, IL6 , IL-1 $\beta$, and TNF- $\alpha$ expressions; the primers were designed and synthesized by Sangon Biotech Co., Ltd. (Shanghai, China); primers are listed in Table 1. Relative mRNA expression levels of genes were normalized by GADPH.

\section{Western Blot}

The samples of $16 \mathrm{HBE}$ cells and PQ-treated mice were collected, total protein was extracted using RIPA lysis buffer (Beyotime Biotechnology, Shanghai, China), and the protein concentration was determined with

Table 1. Quantitative PCR Primers Used in the Study

\begin{tabular}{|c|c|}
\hline Gene & Primer sequences (strand) \\
\hline Keap1 & $\begin{array}{l}\text { Forward: 5'-CTACCTGGAGGCTTACAAC-3' } \\
\text { Reverse: 5'-CATACCTCTCCACACTGTTG-3' }\end{array}$ \\
\hline p65 & $\begin{array}{l}\text { Forward: 5'-AGATGGAGCCAGAGAACAAG-3' } \\
\text { Reverse: 5'-TAAGAGCATAAGCCTCACATG-3' }\end{array}$ \\
\hline Nrf2 & $\begin{array}{l}\text { Forward: 5'- CTCAGTCACCTGAAACTTCTG-3' } \\
\text { Reverse: 5'-GCTGATACTGGGCTCAGCTATG-3' }\end{array}$ \\
\hline IL-4 & $\begin{array}{l}\text { Forward: 5'-TGAGTGAGTGGTGGGGTCCTTAC-3' } \\
\text { Reverse: 5'-CACTATGTTGCCTAGGCTCATCTC-3' }\end{array}$ \\
\hline IL-6 & $\begin{array}{l}\text { Forward: 5'-CCAATTTCCAATGCTCTCCT-3' } \\
\text { Reverse: 5'-ACCACAGTGAGGAATGTCCA-3' }\end{array}$ \\
\hline IL-1 $\beta$ & $\begin{array}{l}\text { Forward: 5'-ACAGTGGCAATGAGGATGAC-3' } \\
\text { Reverse: 5'-GTTCATATGGACCAGACATC-3' }\end{array}$ \\
\hline TNF- $\alpha$ & $\begin{array}{l}\text { Forward: 5'-AGAAGGAAACAGACCACAGACC-3' } \\
\text { Reverse: 5'-TCTGTAGTTGCTTCTCTCCCTC-3' }\end{array}$ \\
\hline GAPDH & $\begin{array}{l}\text { Forward: 5'-AGAAGGCTGGGGCTCATTTG-3' } \\
\text { Reverse: 5'-AGGGGCCATCCACAGTCTTC-3' }\end{array}$ \\
\hline
\end{tabular}

BCA Protein Assay Kit (Beyotime Biotechnology, Shanghai, China). Protein was then solubilized in $2 \times$ sample buffer; SDS-polyacrylamide gel electrophoresis was then performed to separate the targeted proteins. The proteins were then transferred to polyvinylidene difluoride (PVDF) membranes (Bio-Rad, Hercules, USA) and the membranes were incubated with $5 \%$ bovine serum albumin (BSA) for $60 \mathrm{~min}$ at the room temperature. The primary antibodies of anti-Keap1 (1:1000, \#K2769, Sigma, USA), anti-p65 (1:1000, \#P0 068 , Sigma, USA), anti-Nrf2 (1:500, \#SAB4501984, Sigma, USA), anti-p21 (1:1000, \#SAB4500065, Sigma, USA), anti-Cyclin A2 (1:1000, \#C4710, Sigma, USA), anti-Cyclin D1 (1:1000, \#C7464, Sigma, USA), anti-Bax (1:500, \#B8429, Sigma, USA), anti-Bcl-2 (1:1000, \#B3170, Sigma, USA), anti-Caspase 3 (1:500, \#C8487, Sigma, USA), anti-LC-3 (1:1000, \#8918, Sigma, USA), and anti- $\beta$-actin (1:1000, \#A5441, Sigma, USA) were employed to be incubated with the membranes overnight at $4{ }^{\circ} \mathrm{C}$. The anti-mouse IgG-peroxidaseconjugate secondary antibodies (Sigma, USA) were used to be incubated with the membrane for $2 \mathrm{~h}$ at the room temperature to combine to the primary antibodies. The bands were visualized by Enhanced Chemiluminescence Kit (Bio-Rad, USA) and ChemiDoc (Bio-Rad, USA); the expressions were quantified by ImageJ software. Each assay was repeated for at least 3 times to eliminate deviations.

\section{CRISPR-Cas9 Technology Was Used to Knockout Nrf2 in 16HBE Cells}

CRISPR-Cas9 technology was conducted to knockout Nrf2 gene according to the protocol from Dr. Zhang F. The two sgRNAs targeting human Nrf2 were designed and constructed into pSgRNA (addgene\#47108) using Bbs1 digestion (sgRNA sequences, F1:CAATTAAGGCATGGAATTCCCAT, R1: A A A C C TAT T C C C A GA G T C A G T C A; F 2: CATTCCTCCAGGACCCTAGGATGCAGT, R2: AAACGTTCGAACTCTGAC-GGTA). In addition, the constructed plasmids and pCas9-GFP (addgene\#44719) were transfected into 16HBE cells by Lipofectamine 3000 transfection reagent (\#13778150, Invitrogen, USA) according to the manufacturer's instructions. Approximately $1 \times 10^{6}$ cells were transfected with $1 \mu \mathrm{g}$ pCas9 plasmids, $1 \mu \mathrm{g}$ pSgRNAs, and $0.2 \mu \mathrm{g}$ PKG-puro plasmid with puromycin resistance gene. Puromycin $(1.5 \mu \mathrm{g} / \mathrm{ml})$ was 
then co-cultured with cells to select puromycin resistance cells. Total proteins were then extracted from the cells and Western Blot was used to verify the transfection efficiency of the plasmids.

\section{p65 Overexpression Plasmid Construction and Transfection}

To overexpress cellular p65 expression levels, the coding sequence (GenBank S82307.1) for the human p65 gene was obtained from the total RNA of human HEK293T cells isolated by using TRIzolreragent (Takara Bio, Kusatsu, Japan) and then transcribed using iScript cDNA Synthesis Kit (Bio-Rad, Hercules, CA, USA). The sequences were then cloned into the pEGFP-N1 gene overexpression vectors, and the pEGFP-N1-p65 overexpression vectors were transfected into $16 \mathrm{HBE}$ cells by Lipofectamine 3000 transfection reagent (\#13778150, Invitrogen, USA) according to the manufacturer's instructions; the pEGFP-N1 empty vectors were used as the negative control. Western Blot was used to verify that the vectors were successfully transfected into the target cells.

\section{Flow Cytometry}

16HBE cells treated with PQ were collected and prepared by GE Ficoll-Paque PLUS (GE, USA); cells were then treated with $10 \%$ DMSO and stored in $-80^{\circ} \mathrm{C}$. Ex vivo cellular staining for Annexin-V and PI was implemented by incubating cells with specific dyes (Thermo Fisher, USA) following the manufacturer's instructions. Attune NxT Flow Cytometer (Thermo Fisher, USA) was used to collect the data of cell necrosis, early apoptosis, and late apoptosis. Each assay had at least 3 repetitions.

\section{Detection of ROS Levels}

$16 \mathrm{HBE}$ cells were treated with $500 \mu \mathrm{M}$ of PQ for $0 \mathrm{~h}$, $12 \mathrm{~h}, 24 \mathrm{~h}$, and $48 \mathrm{~h}$; L-012 dye was used to detect extracellular NADPH oxidase-derived superoxide. In brief, $16 \mathrm{HBE}$ cells were diluted into approximately $4-6 \times 10^{4}$ cells/well into 96-well plates (Thermo, USA) in phenolfree DMEM medium (Sigma, USA) with L-012 at the concentration of $500 \mu \mathrm{M}$ according to our preliminary experiments (data not shown) for $10 \mathrm{~min}$ and luminescence was detected by a Gemini EM microplate reader (Molecular Devices, USA) at the excitation wavelength of $488 \mathrm{~nm}$ and emission wavelength of $525 \mathrm{~nm}$ respectively. Cellular ROS levels were next measured by dihydroethidium (DHE) staining. Cells were washed with PBS twice and diluted; $10 \mu \mathrm{M}$ of DHE (Invitrogen, USA) was selected according to our preliminary experiments (data not shown) to incubate with the cells for $30 \mathrm{~min}$ at $37{ }^{\circ} \mathrm{C}$ without light exposure. After incubation, cells were washed with PBS and DM500 fluorescence microscope (Leica, Germany) was employed to observe ROS productions. The fluorescence intensity was quantified and calculated by ImageJ software.

\section{Statistical Analysis}

All the data collected in our experiments was showed as the mean \pm standard deviation (SD), and the data was analyzed by SPSS 13.0 statistical software with one-way analysis of variance (ANOVA) for multiple groups and Student's $t$ test for two groups. $P<0.05$ means statistical significance.

\section{RESULTS}

\section{Cell Proliferation and Apoptosis of 16HBE Cells Treated with Different Doses of PQ}

Previous study proved that PQ induces cell intoxication in a dose-dependent manner [20]. In our study, 16HBE cells were treated with $50 \mu \mathrm{M}, 150 \mu \mathrm{M}$, and $500 \mu \mathrm{M}$ PQ for $12 \mathrm{~h}, 24 \mathrm{~h}, 48 \mathrm{~h}$, and $72 \mathrm{~h}$ respectively; the results showed that the inhibiting effects of PQ on cell proliferation were positively correlated with PQ concentration and treating time (Fig. 1a-b), which were in line with the previous study [9]. The Western Blot results also showed that PQ $(150 \mu \mathrm{M}, 48 \mathrm{~h})$ significantly increases p21 and decreases cyclin A2 as well as cyclin D1 in 16HBE cells (Fig. 1c-d), which indicated that cell cycle arrest is induced by PQ treatment. After treating cells with different concentrations of PQ $(50 \mu \mathrm{M}, 150 \mu \mathrm{M}$, and $500 \mu \mathrm{M})$ for $2 \mathrm{~h}, 4 \mathrm{~h}$, and $8 \mathrm{~h}$, respectively, the FCM results showed that PQ induces cell death and apoptosis in a dose-dependent manner (Fig. 1e). Of note, PQ specifically induces cell necrosis and late apoptosis instead of early apoptosis in 16HBE cells (Fig. 1f-h). In addition, pro-apoptotic proteins caspase 3 as well as Bax are increased, and anti-apoptotic protein Bcl-2 is decreased in $16 \mathrm{HBE}$ cells treated with $150 \mu \mathrm{M}$ of PQ for $48 \mathrm{~h}$ compared with the control group (Fig. 1i-j).

\section{ROS Production in 16HBE Cells Treated with Different Doses of PQ}

According to the previous studies, ROS generation was pivotal for PQ-induced cell intoxication and 

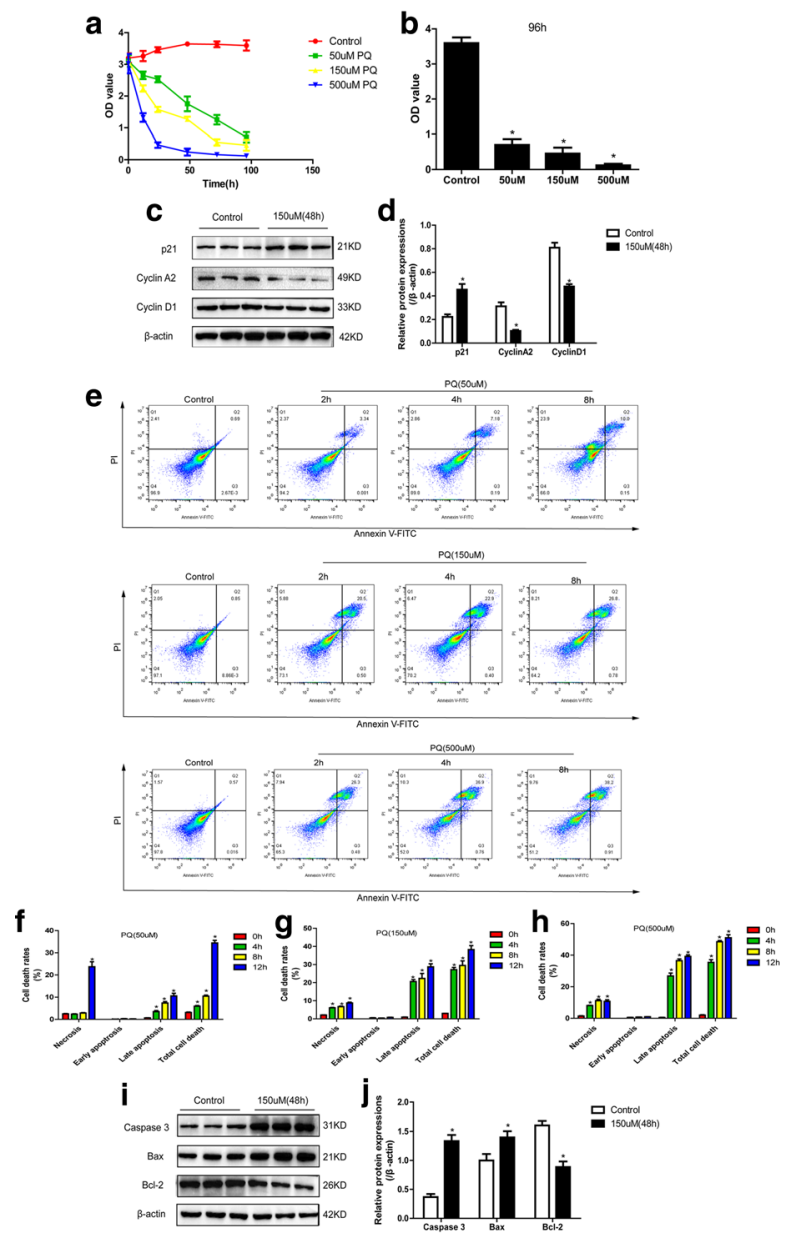

Fig. 1. Different concentrations $(50 \mu \mathrm{M}, 150 \mu \mathrm{M}$, and $500 \mu \mathrm{M})$ of PQ's influences on cell proliferation and apoptosis. a CCK-8 assay showed that PQ inhibits cell proliferative ability in time- and dose-dependent manners. b CCK-8 assay was used to detect different doses of PQ's influences on cell proliferation at $96 \mathrm{~h}$. $\mathbf{c}$ Cell cycle-associated proteins of $16 \mathrm{HBE}$ cells treated with PQ $(150 \mu \mathrm{M})$ for $48 \mathrm{~h}$ were detected by Western Blot. d Quantification of cell cycle-associated proteins by ImageJ software. e Cell death rates were detected by FCM in $16 \mathrm{HBE}$ cells treated with different doses of PQ at $2 \mathrm{~h}, 4 \mathrm{~h}$, and $8 \mathrm{~h}$ respectively. $\mathbf{f}, \mathbf{g}, \mathbf{h}$ Necrosis, early apoptosis, late apoptosis, and total cell death were counted according to the FCM results. i Apoptosis-associated proteins were detected by Western Blot in 16HBE cells treated with $150 \mu \mathrm{M}$ PQ for $48 \mathrm{~h}$. j Apoptosis-associated proteins were quantified by ImageJ software according to the Western Blot results. Each assay in the experiments had 3 repetitions (the data are presented as mean $\pm \mathrm{SD}$, “*” means statistical significance, $p<0.05$ ).

lung fibrosis [7, 21]. Given the fact that ROS generation induces cell death and apoptosis [22], we next explored the extracellular superoxide release and ROS production in $16 \mathrm{HBE}$ cells treated with PQ. After treating $16 \mathrm{HBE}$ cells with PQ $(50 \mu \mathrm{M}$, $150 \mu \mathrm{M}$, and $500 \mu \mathrm{M}$ ) for $48 \mathrm{~h}, \mathrm{~L}-012$ assay results showed that extracellular superoxide production was increased by PQ treatments in a dose-dependent manner (Fig. 2a-b). The DHE staining data also showed the similar results; low doses $(50 \mu \mathrm{M}$ and $150 \mu \mathrm{M})$ of PQ slightly increase ROS levels at $12 \mathrm{~h}$ and $24 \mathrm{~h}$, while high dose $(500 \mu \mathrm{M})$ of PQ significantly increases ROS levels at $12 \mathrm{~h}$ (Fig. 2c-h), which indicated that PQ also induces ROS production in a dose-dependent manner, and our results were in accordance with the previous study [20].

\section{Cell Autophagy Was Affected in 16HBE Cells Co- Cultured with Different Doses of PQ}

Cell autophagy has been reported to be closely related with PQ-induced cell intoxication [6]; since autophagy has dual effects on cells' responses to environmental stress including ROS generation [23, 24], we next explored 
a

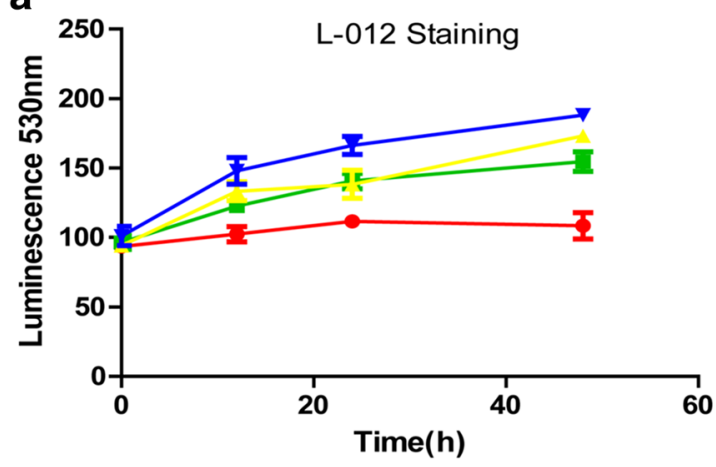

b

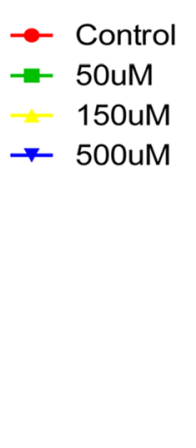

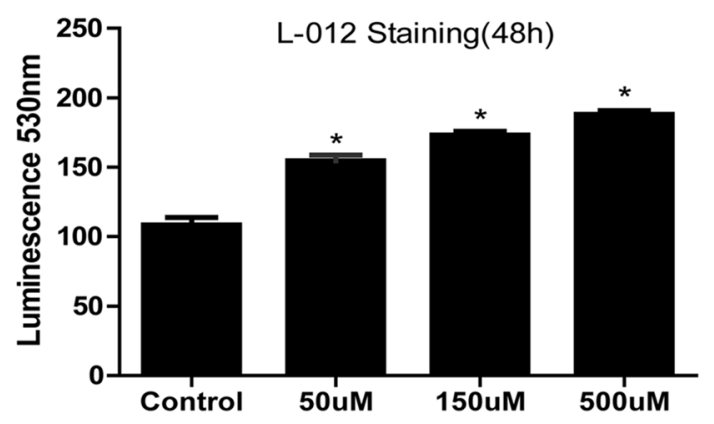
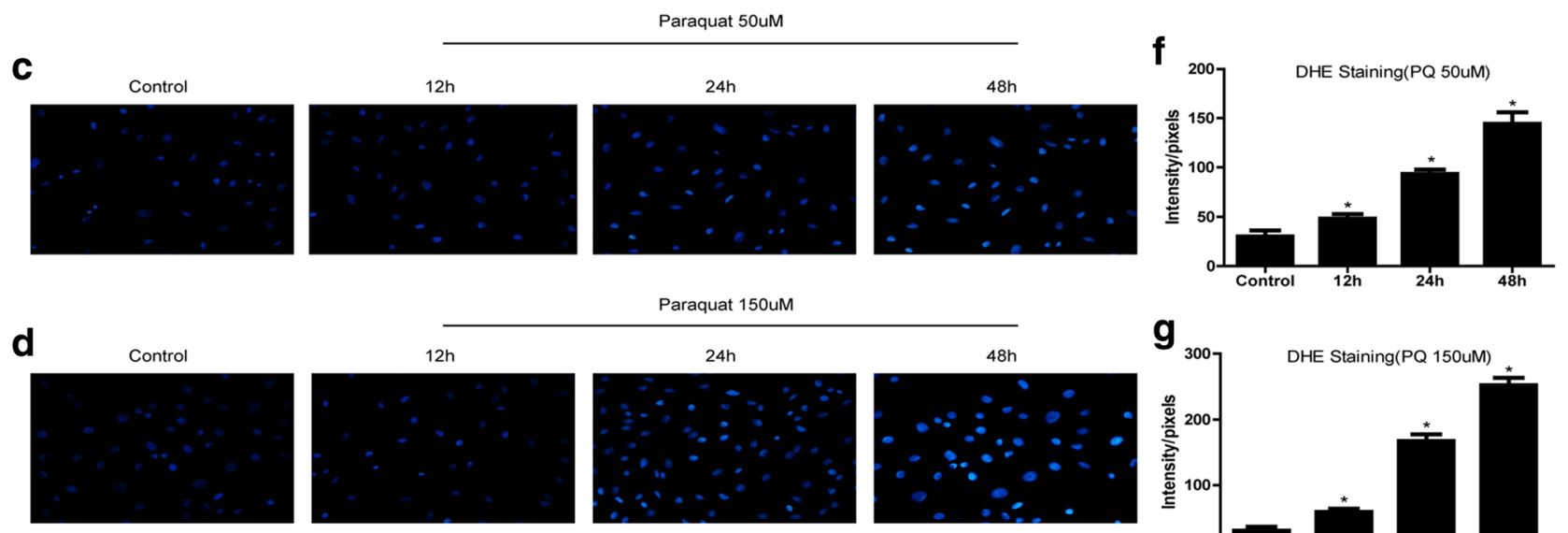

Paraquat $150 u$ M
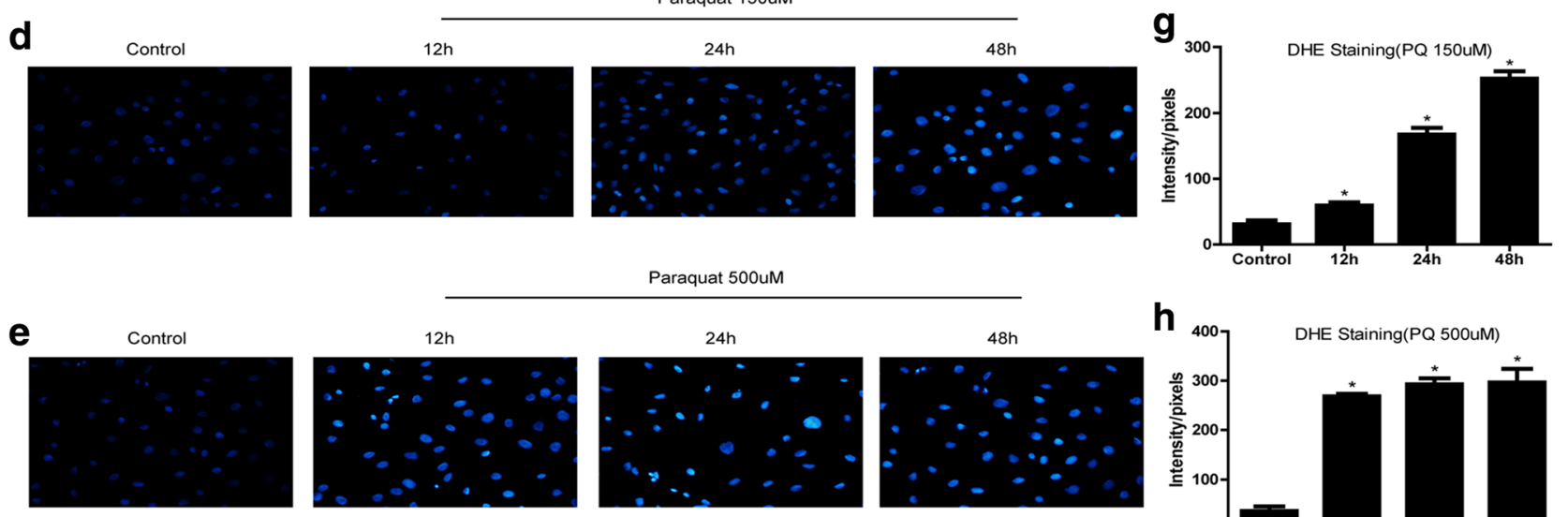

Paraquat 500uM
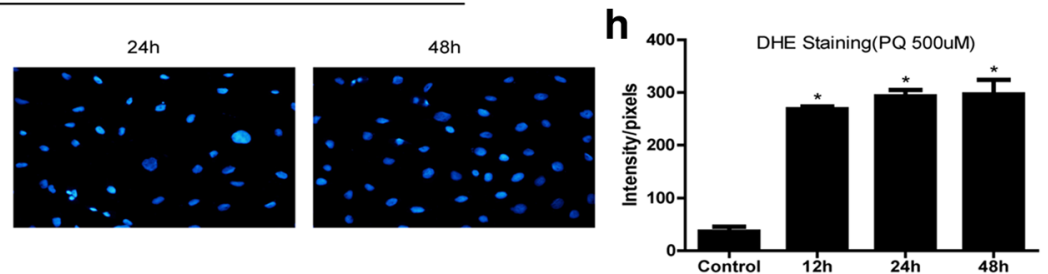

Fig. 2. PQ causes a rise in intracellular ROS level and increased cell ROS generation. a $16 \mathrm{HBE}$ cells were subjected to different doses of PQ (50 $\mu \mathrm{M}$, $150 \mu \mathrm{M}$, and $500 \mu \mathrm{M}$ ) at $12 \mathrm{~h}, 24 \mathrm{~h}$, and $48 \mathrm{~h}$, respectively, and the superoxide release was monitored by chemiluminescence dye L- 012 . b The luminescence values of L-012 dye in $16 \mathrm{HBE}$ cells treated with PQ $(50 \mu \mathrm{M}, 150 \mu \mathrm{M}$ and, $500 \mu \mathrm{M})$ for $48 \mathrm{~h}$. $\mathbf{c}, \mathbf{d}$, e Images and $\mathbf{f}, \mathbf{g}, \mathbf{h}$ quantification of dihydroethidium (DHE) staining for intracellular ROS by ImageJ software, the original objective magnification is $\times 40$. Each assay in the experiments had at least 3 repetitions (the data are presented as mean $\pm \mathrm{SD}$, “*” means statistical significance).

PQ's influences on cell autophagy by electronic microscope and Western Blot. 16HBE cells were treated with different doses of PQ $(50 \mu \mathrm{M}$ and $500 \mu \mathrm{M})$ for $8 \mathrm{~h}$; the images of electronic microscope showed that low dose of PQ $(50 \mu \mathrm{M})$ induces autophagosome production in $16 \mathrm{HBE}$ cells, and the number of autophagosome dramatically decreased in $16 \mathrm{HBE}$ cells by treating cells with $500 \mu \mathrm{M}$ of PQ (Fig. 3a). 16HBE cells were next treated with different doses of PQ $(50 \mu \mathrm{M}, 150 \mu \mathrm{M}$, and $500 \mu \mathrm{M})$ for $0 \mathrm{~h}, 12 \mathrm{~h}$, $24 \mathrm{~h}, 48 \mathrm{~h}$, and $96 \mathrm{~h}$ respectively; Western Blot results showed that $50 \mu \mathrm{M}$ of PQ significantly increases LC3-II/ LC3-I ratios and decreases p62 levels at $24 \mathrm{~h}, 48 \mathrm{~h}$, and 96 h compared with the control group (Fig. 3b-d). Notably, compared with the control group, $150 \mu \mathrm{M}$ of PQ merely increases LC3-II/LC3-I ratios at $12 \mathrm{~h}$, which significantly decreases at 24 h, 48 h, and 96 h (Fig. 3e-f); p62 is also 

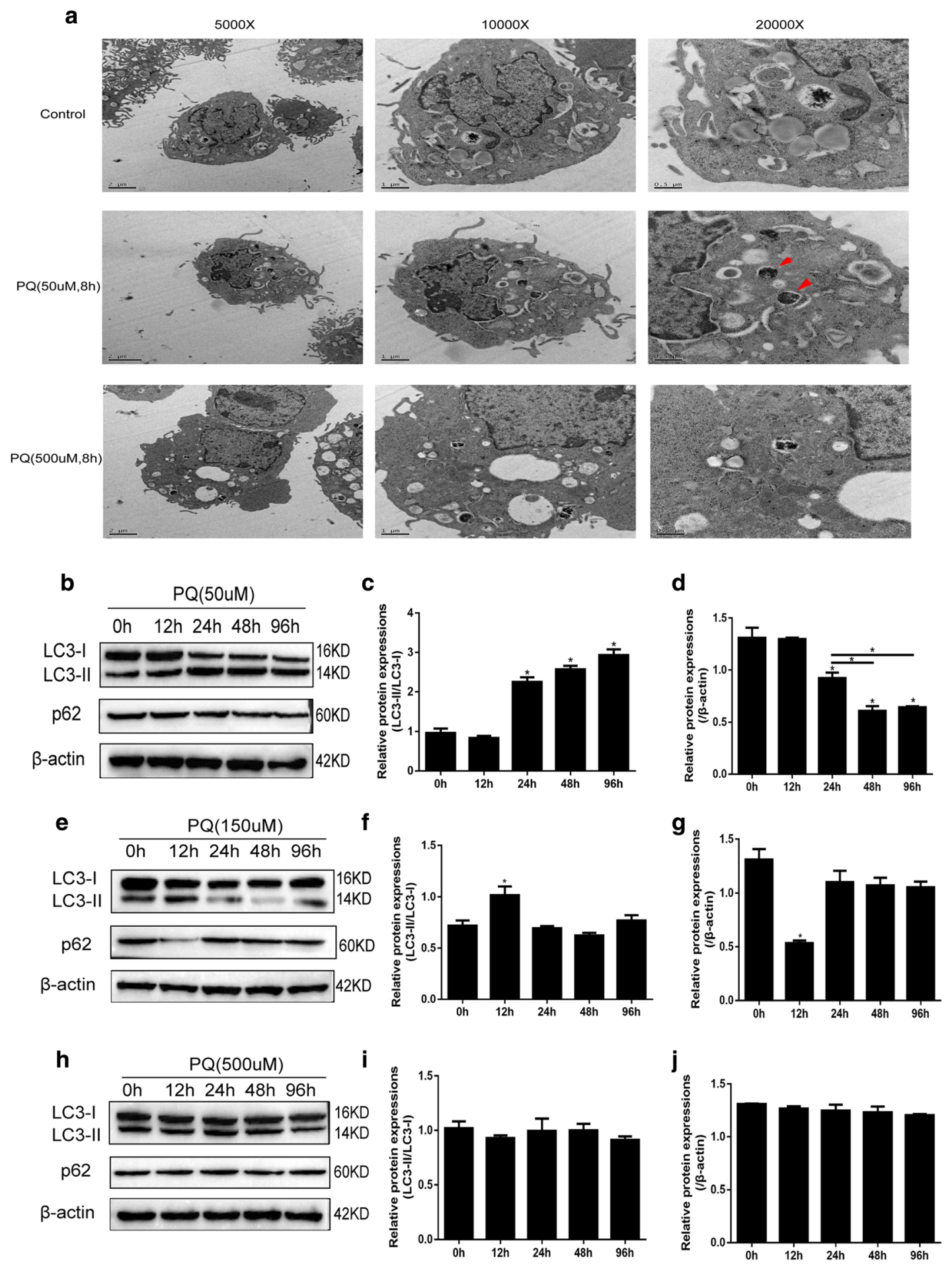

Fig. 3. Different doses of PQ $(50 \mu \mathrm{M}, 150 \mu \mathrm{M}$, and $500 \mu \mathrm{M})$ had various impacts on cell autophagy. a Electronic microscope was used to observed cell autophagosomes in 16HBE cells treated with PQ $(50 \mu \mathrm{M}$ and $500 \mu \mathrm{M})$ for $8 \mathrm{~h}$, the red arrows indicate the autophagosomes. b, e, h Western Blot was employed to detect cell autophagy-associated proteins in 16HBE cells treated with PQ $(50 \mu \mathrm{M}, 150 \mu \mathrm{M}$, and $500 \mu \mathrm{M})$ for $0 \mathrm{~h}, 12 \mathrm{~h}, 24 \mathrm{~h}, 48 \mathrm{~h}$, and $96 \mathrm{~h}$ respectively. c, $\mathbf{d}, \mathbf{f}, \mathbf{g}, \mathbf{i}, \mathbf{j}$ Quantification of autophagy-associated proteins was conducted by ImageJ software according to the Western Blot results. Each assay in the experiments had at least 3 repetitions (the data are presented as mean $\pm \mathrm{SD}$, “*” means statistical significance, $p<0.05$ ). 
downregulated by $150 \mu \mathrm{M}$ of PQ at $12 \mathrm{~h}$ (Fig. 3e, g). In addition, $500 \mu \mathrm{M}$ of PQ has little impacts on either LC3-II/ LC3-I ratios or p62 at any time point (Fig. 3h-j).

\section{PQ's Influences on p65 and the Activation of Keap1/ Nrf2 Signal Pathway}

Our results showed that ROS generation plays an important role in $\mathrm{PQ}$-induced cell intoxication, since Keap1/Nrf2 signal pathway is closely related with the regulation of ROS production [25], and p65 might influence Nrf2 by binding to its inhibitor Keap1 [17]. We next investigated the involvement of $\mathrm{p} 65$ and Keap1/Nrf2 signal pathway in 16HBE cells treated with PQ. 16HBE cells were treated with various doses of PQ $(50 \mu \mathrm{M}, 150 \mu \mathrm{M}$, and $500 \mu \mathrm{M}$ ) for $48 \mathrm{~h}$; real-time qPCR results showed that $50 \mu \mathrm{M}$ and $150 \mu \mathrm{M}$ of PQ has little effects on Keap1 expressions compared with the control group, but Keap1 mRNA expression levels are significantly increased by treating 16HBE cells with $500 \mu \mathrm{M}$ of PQ (Fig. 4a). Notably, $50 \mu \mathrm{M}$ of PQ significantly increases p65 and Nrf2 mRNA expressions, which are surprisingly decreased by high doses of PQ $(150 \mu \mathrm{M}$ and $500 \mu \mathrm{M})$ (Fig. 4b-c). Further Western Blot results also showed that Keap1 is merely increased by treating cells with $500 \mu \mathrm{M}$ of PQ. Besides, p65 and Nrf2 are upregulated by $50 \mu \mathrm{M}$ of PQ, which are downregulated by treating $16 \mathrm{HBE}$ cells with high doses of PQ $(150 \mu \mathrm{M}$ and $500 \mu \mathrm{M})$ (Fig. 4d-e). The results also showed that Keap1 is not affected by p65 overexpression or knock-down (Fig. 4f-g). However, Nrf2 is significantly upregulated by p65 overexpression and downregulated by p65 knock-down compared with the control group (Fig. $4 \mathrm{f}-\mathrm{g}$ ). In addition, overexpressed p65 promotes Nrf2 downstream targets Nqo1 and Gclc expressions, which are reversed by synergistically knocking down Nrf2 (Fig. 4h-i). Furthermore, overexpressed p65 reverses $500 \mu \mathrm{M}$ of PQ's inhibiting effects on Nrf2 (Fig. 4h-i).

\section{Involvement of Keap1/p65/Nrf2 Signal Pathway in PQ- Induced Cell Intoxication}

To explore the role of Keap1/p65/Nrf2 signal pathway in PQ-induced cell intoxication, we first overexpressed p65 or synergistically overexpressed p65 and knocked down Nrf2 in 16HBE cells (Fig. 5a-b). By treating cells with $500 \mu \mathrm{M}$ of PQ for $12 \mathrm{~h}, 24 \mathrm{~h}, 48 \mathrm{~h}, 72 \mathrm{~h}$, and $96 \mathrm{~h}$, we found that cell proliferation is significantly inhibited by PQ in a timedependent manner (Fig. 5c). Of note, overexpressed p65 alleviates PQ's inhibiting effects on cell proliferation, which are reversed by synergistically knocking down Nrf2 (Fig. 5c-d). The FCM results showed that PQ $(150 \mu \mathrm{M}, 2 \mathrm{~h})$ apparently increases $16 \mathrm{HBE}$ apoptosis ratio (Fig. 5e). Similarly, overexpressed p65 attenuates cell apoptosis, which is reversed by synergistically knocking down Nrf2 (Fig. 5e-f). In addition, compared with the control group and PQ-alone-treated group $(500 \mu \mathrm{M})$, overexpressed p65 increases LC3-II/I ratio and decreases p62, which are also reversed by synergistically knocking down Nrf2 (Fig. 5g-i).

\section{Verification of Keap1/p65/Nrf2 Signal Pathway in PQ- Induced Acute Lung Intoxication by In Vivo Experiments}

To investigate the involvement of Keap1/p65/Nrf2 signal pathway activation in PQ-induced cell intoxication and lung fibrosis by in vivo experiments, male C57BL/6 mice were administered with $500 \mu \mathrm{M}$ of PQ for $96 \mathrm{~h}$ to establish PQ-induced lung injury mice models. We first verified that we have successfully overexpressed p65 and knocked down Nrf2 in mice models (Fig. 6a-b). Masson staining images showed that lung fibrosis is induced by high-dose PQ treatment. Overexpressed p65 alleviates PQ-induced tissue morphology destruction, which is reversed by synergistically knocking down Nrf2 (Fig. 6c). PQ-induced lung fibrosis has also been reported to be seriously aggravated by inflammatory reactions; to investigate the role of Keap $1 / \mathrm{p} 65 / \mathrm{Nrf} 2$ signal pathway in regulating inflammatory reactions, real-time qPCR was used to detect inflammatory cytokine mRNA expression levels in lung tissues and ELISA was employed to detect their expressions in mice periphery blood (Fig. $6 d-e)$. The results showed that high dose of PQ increases IL-4, IL-6, IL-1 $\beta$, and TNF- $\alpha$ expressions in both mice lung tissues and periphery blood (Fig. 6d-e). Similarly, overexpressed p65 decreases IL-4, IL-6, IL$1 \beta$, and TNF- $\alpha$ levels in mice, which are reversed by knocking down Nrf2 (Fig. 6d-e). In addition, we found that PQ increases Bax and caspase 3 decreases Bcl-2 in mice tissues. Overexpressed p65 reverses PQ's effects on the apoptosis-associated proteins, which are abrogated by synergistically overexpressing Nrf2 (Fig. 6fg). Furthermore, overexpressed p65 also decreases p 21 and increases cyclin A2 as well as cyclin D1 in mice compared with the PQ-treated group, which are also reversed by knocking down Nrf2 (Fig. 6h-i). 
a

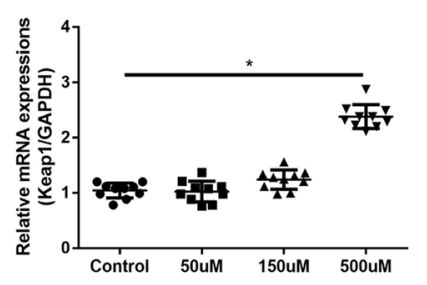

d

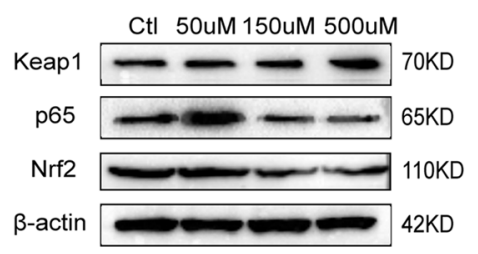

f

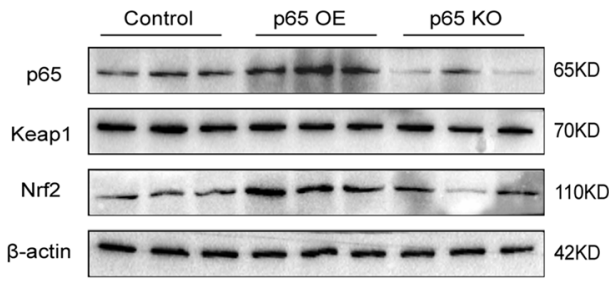

h

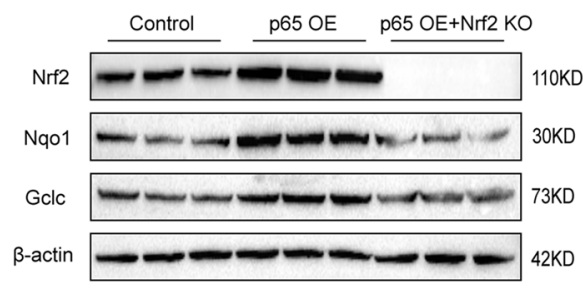

j

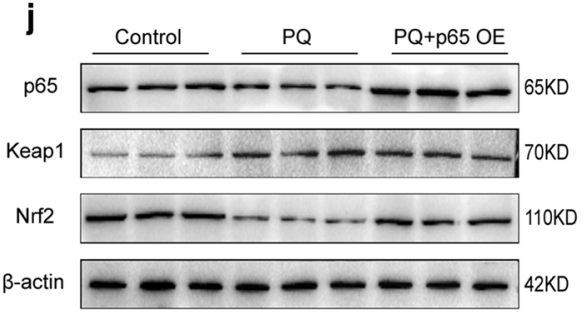

b

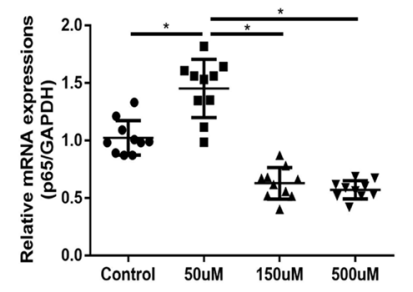

e

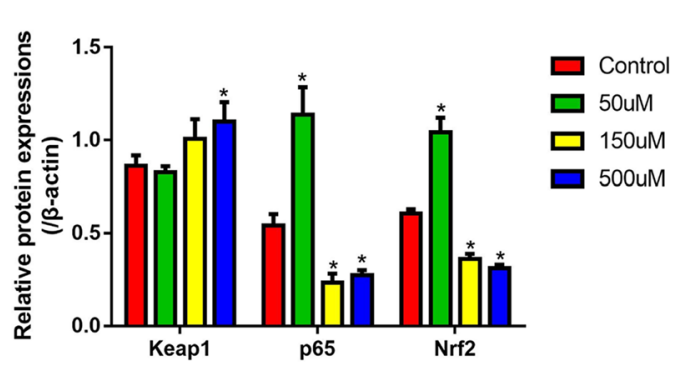

g

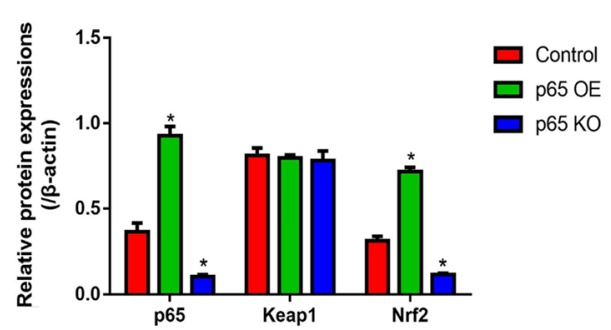

i
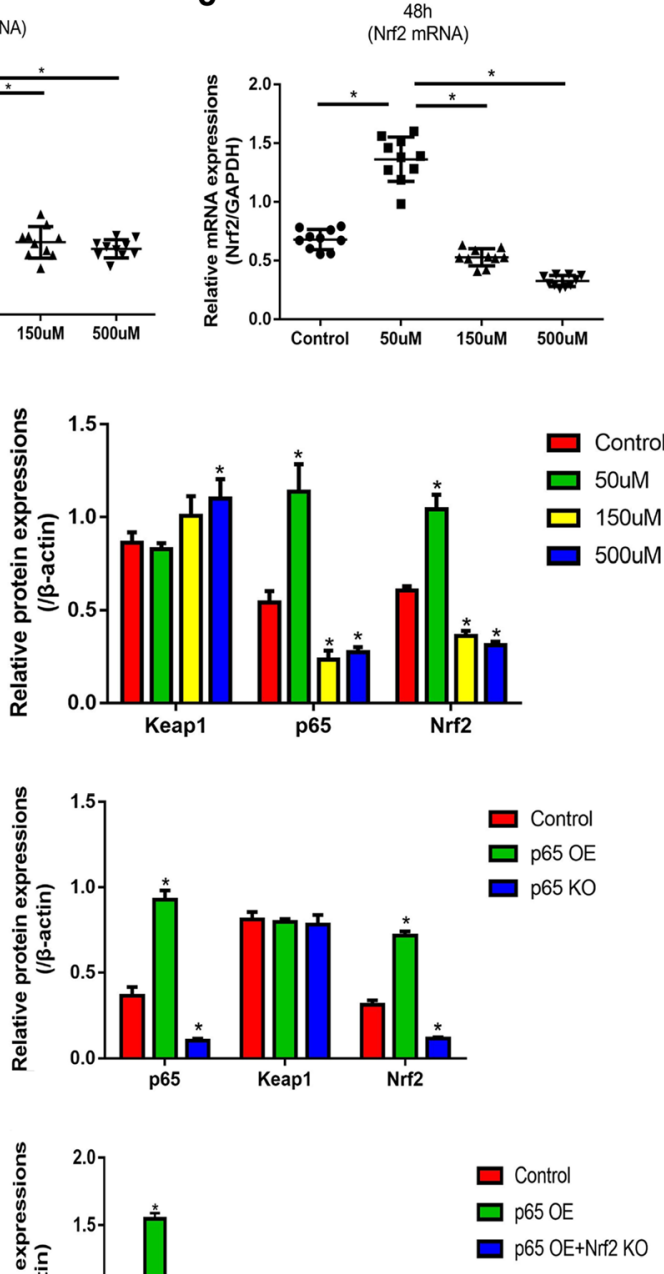
a

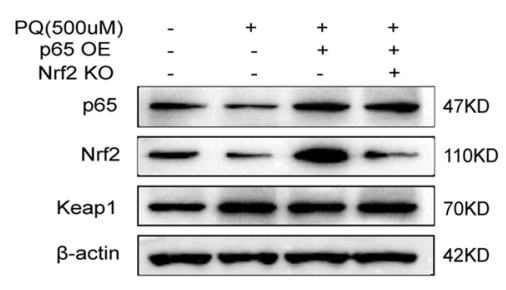

b

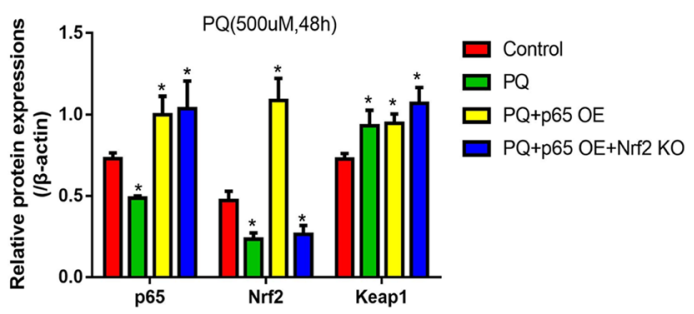

C

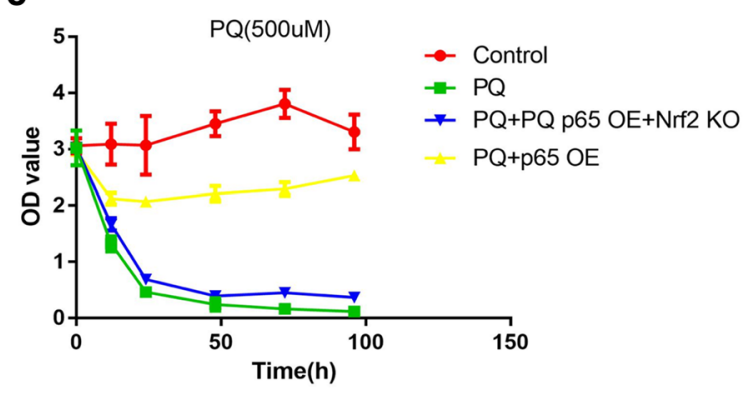

e

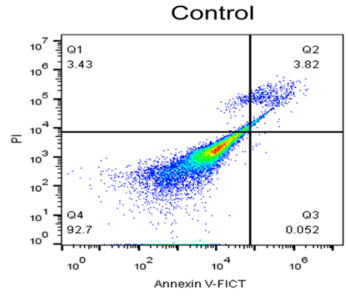

$P Q+p 65$ OE

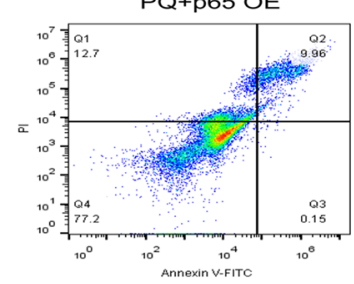

g

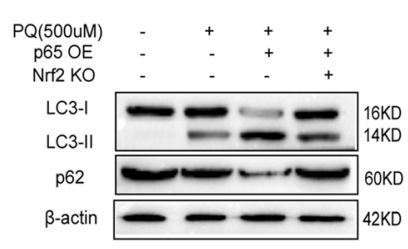

$P Q$

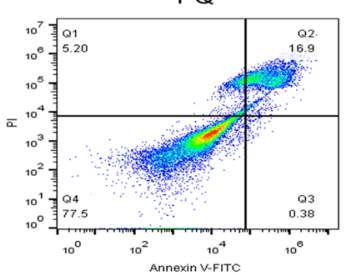

$P Q+p 65 O E+N r f 2 K O$

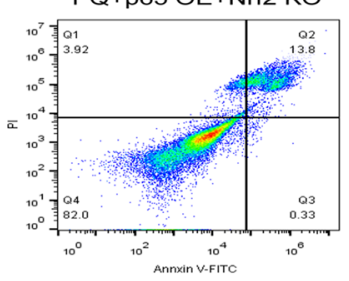

h d
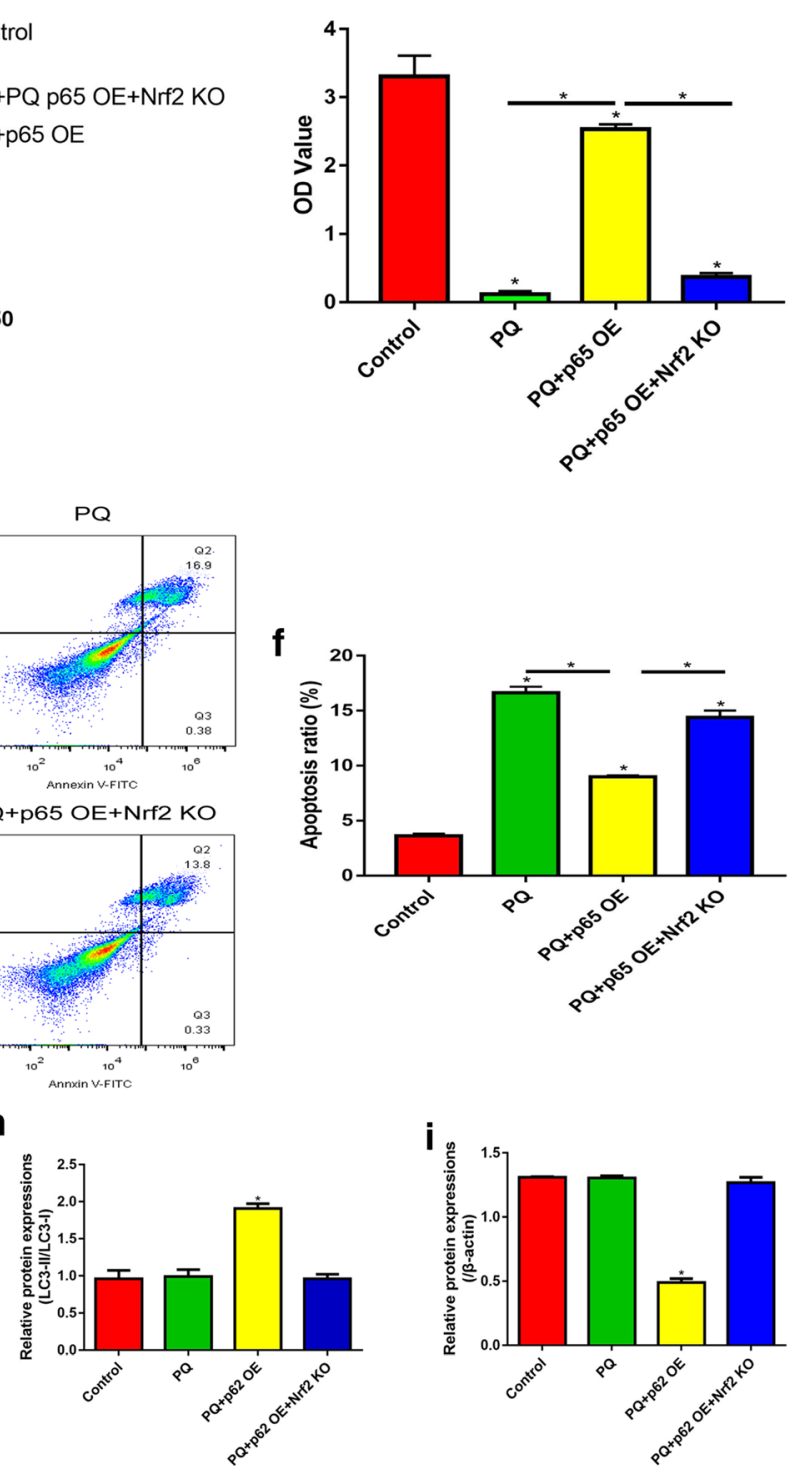

Fig. 5. PQ regulates cell proliferation, cell death, and autophagy by modulating Keap $1 / \mathrm{p} 65 / \mathrm{Nrf} 2$ signal pathway. a, b Western Blot was used to verify the efficiency of p65 overexpression and Nrf2 knock-down in 16HBE cells. c, d The proliferative ability of $16 \mathrm{HBE}$ cells treated with $500 \mu \mathrm{M}$ of PQ for $12 \mathrm{~h}$, $24 \mathrm{~h}, 48 \mathrm{~h}, 72 \mathrm{~h}$, and $96 \mathrm{~h}$ was detected by CCK-8 assay. e, f The apoptosis ratio of $16 \mathrm{HBE}$ cells treated with $150 \mu \mathrm{M}$ PQ for $2 \mathrm{~h}$ was detected by FCM. $\mathbf{g}-\mathbf{i}$ The autophagy-associated proteins of 16HBE cells treated with $500 \mu \mathrm{M}$ of PQ for $48 \mathrm{~h}$ were detected by Western Blot. Each assay had 3 repetitions (the data are presented as mean $\pm \mathrm{SD}$, “*” means statistical significance, $p<0.05)$. 

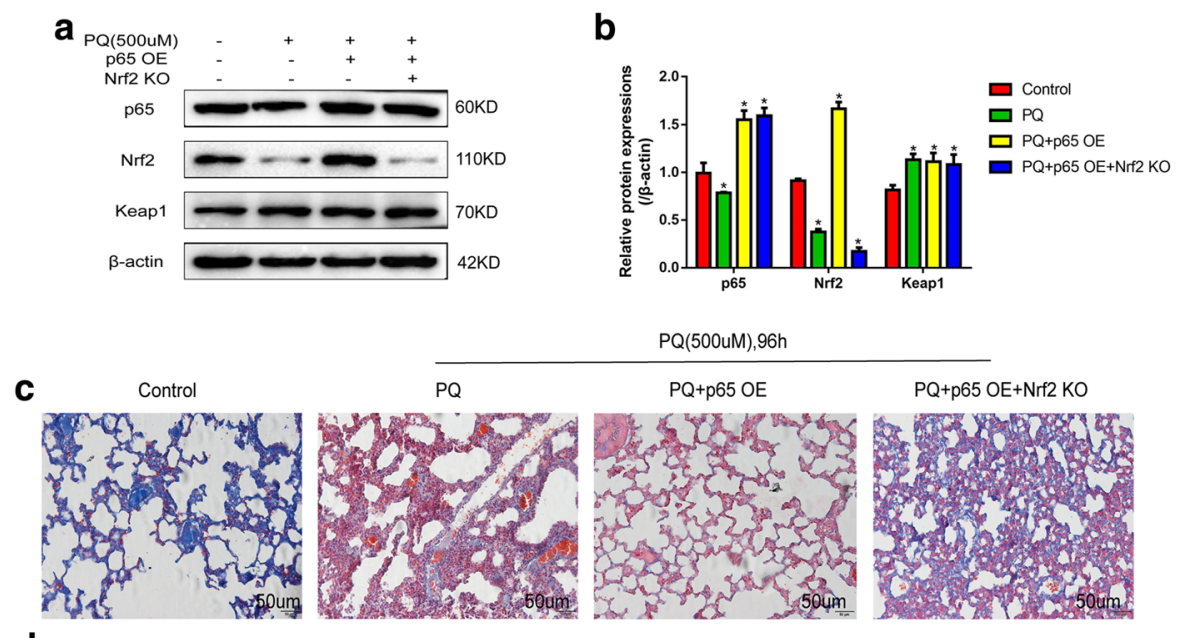

d
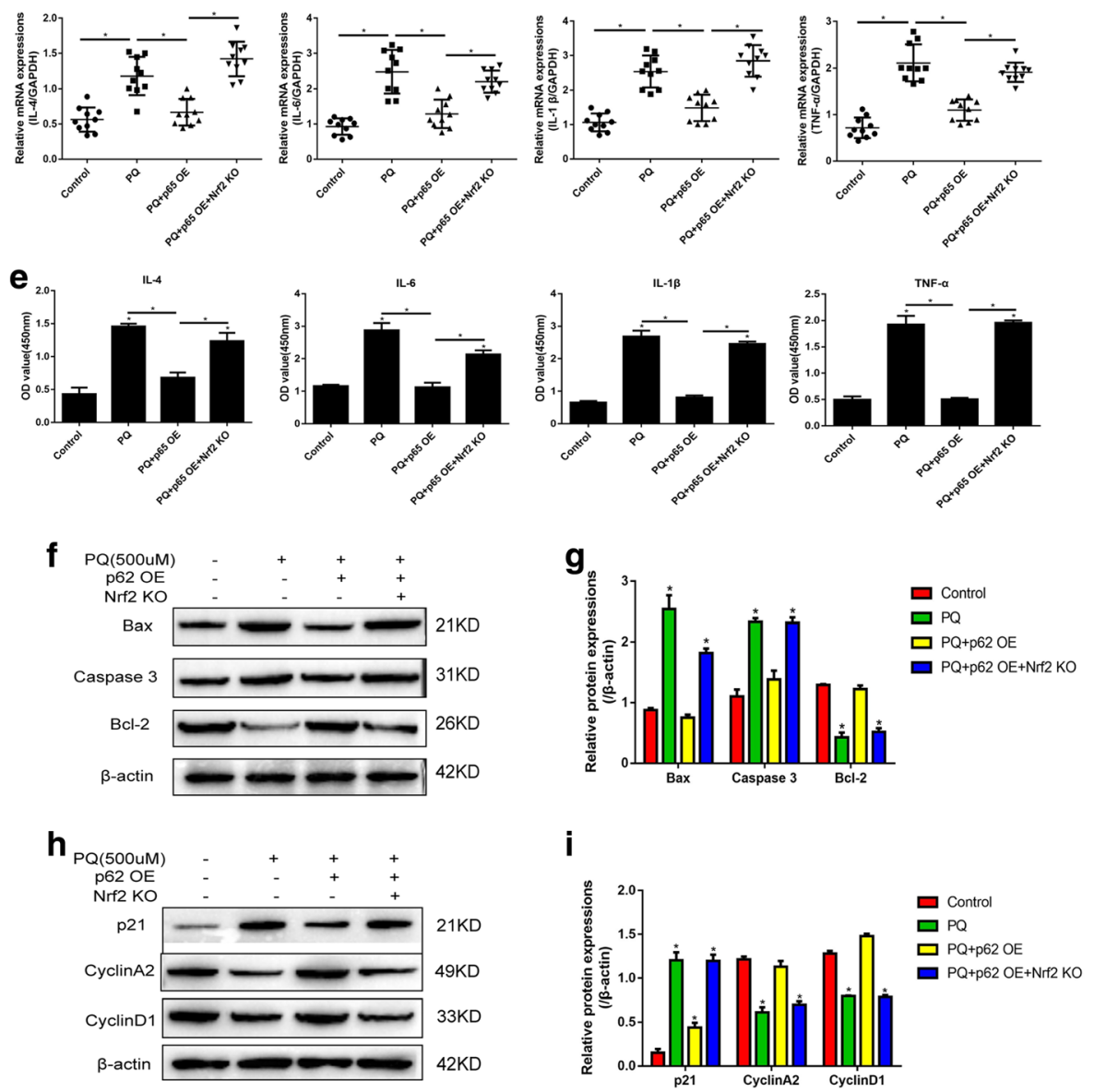

Fig. 6. In vivo experiments prove that $\mathrm{PQ}$ induced cell intoxication by regulating Keap1/p65/Nrf2 signal pathway. Wild-type C57BL/6 male mice were intraperitoneal injected with saline or $500 \mu \mathrm{M}$ of PQ and euthanized after $96 \mathrm{~h}$. a, b Western Blot was used to verify and quantify the efficiency of p65 overexpression and Nrf2 knock-out in the lung tissues of the male C57BL/6 mice. $\mathbf{c}$ Masson staining was employed to observe the morphologies of the lung tissues of mice treated with PQ $(500 \mu \mathrm{M}, 96 \mathrm{~h})$. d The relative mRNA expressions of inflammatory cytokines were detected by real-time qPCR in mice lung tissues and normalized by GAPDH. e The expressions of inflammatory cytokines in the periphery blood of the mice were detected by ELISA. $\mathbf{f}, \mathbf{g}$ Cell apoptosis-associated proteins were detected and quantified in the mice lung tissues. $\mathbf{h}, \mathbf{i}$ Cell cycle-associated proteins were detected and quantified in the mice lung tissues. Each assay had at least 3 repetitions (the data are presented as mean $\pm \mathrm{SD}$, “*” means statistical significance, $p<0.05$ ). 


\section{DISCUSSION}

PQ poisoning is a serious problem for human beings because there are currently no effective therapies for its treatment [26]. Studies have proved that PQ preferentially accumulates in patients' lung and induces acute lung injury by regulating ROS-mediated cell death and activating inflammatory reactions [11, 27]. ROS-mediated autophagy-induced cell death also played an important role in PQ-induced cell intoxication [11], but the mechanisms are still unclear. The activation of Keap1/Nrf2 signal pathway was demonstrated to regulate ROS generation and inflammatory reactions [12, 18, 19], and p65 was capable of binding Keap 1 and potentially participated in the inactivation of Keap1/Nrf2 signal pathway [17]. However, it is still unknown whether PQ induced cell intoxication and inflammatory reactions by regulating p65 and Keap1/ Nrf2 signal pathway, and the influences of p65 on Keap1/Nrf2 signal pathway still need to be elucidated.

In our study, we found that PQ inhibits cell proliferation and promotes cell apoptosis in a dosedependent manner, which is in accordance with previous study [20]. Notably, our results showed that PQ preferentially induces necrosis and late apoptosis instead of early apoptosis, which indicated that PQ induces acute cell apoptosis and cell necrosis is another characteristic of PQ-induced cell death; previous study suggested that PQ mainly causes necrosis in human neuronal cells [28], which was in line with our results. Autophagy is also induced by PQ [11, 29]; we found that autophagy is mainly induced by low dose of PQ $(50 \mu \mathrm{M})$ instead of high doses of PQ $(150 \mu \mathrm{M}$ and $500 \mu \mathrm{M})$. The results above suggested that PQ's influences on cell proliferation, autophagy, and death vary according to its concentrations.

Since ROS generation is an important factor in PQinduced cell intoxication [7, 21,30], we next explored PQ's impacts on ROS generation. The results showed that PQ induced ROS generation in $16 \mathrm{HBE}$ cells in a dose-dependent manner. The results are in line with the previous study which reported that PQ-induced neurodevelopmental toxicity by promoting ROS generation [7]. Since it has been reported that ROS generation was closely related with cell autophagy [31], apoptosis [32], and viability [33], therefore, based on our results, we speculated that the effects of different doses of PQ on $16 \mathrm{HBE}$ cells might be associated with ROS generation, but the detailed mechanisms need to be deciphered in the further studies.
The activation of Keap1/Nrf2 signal pathway alleviates ROS generation by regulating AREs [16]; hence, we hypothesized that this signal pathway might participate in the processes of PQ-induced cell intoxication. Our results showed that this signal pathway is merely activated by low dose of PQ instead of high dose of PQ. In addition, Nrf2 is increased by p65 overexpression and decreased by p65 knock-down. Besides, the downstream targets (Nqo1 and Gclc) of Nrf2 are increased by p65 overexpression. Furthermore, overexpressed p65 also reverses high-dose PQ's inhibiting effects on Nrf2 levels, which indicated that p65 promotes the release of Nrf2 and participates in the activation of Keap1/Nrf2 signal pathway.

Overexpressed p65 also decreases cell apoptosis ratio in $16 \mathrm{HBE}$ cells treated with high dose of PQ, which is reversed by synergistically knocking down Nrf2. Interestingly, high-dose PQ's inhibiting effects on cell autophagy and proliferation are recovered by $\mathrm{p} 65$ overexpression, and synergistically knocking down Nrf2 abrogates p65's promoting effects on cell autophagy and proliferation. The results above indicated that PQ modulates cell proliferation, death, and autophagy by regulating Keap1/p65/Nrf2 signal pathway. The in vivo experiments also verified that PQ induces mice lung fibrosis, inhibits cell proliferation, and promotes cell death and inflammatory cytokine secretion by regulating Keap1/p65/Nrf2 signal pathway. The results indicated that PQ triggers acute lung intoxication in mice by regulating Keap1/p65/Nrf2 signal pathway.

In conclusion, we found that high dose of PQ inhibits cell viability and autophagy and promotes cell death as well as mice lung fibrosis by regulating Keap1/p65/Nrf2 signal pathway.

\section{AUTHOR'S CONTRIBUTION}

Z.D. and T.Z. designed the study design and the experiments. J.Y., W.T., and S.D. carried out PCR, Western Blot. T.L., W.L., and L.P. carried out the immunofluorescence staining and fluorescence microscopy. W.T., W.L., and D.F. participated in the design of the study and performed the statistical analysis. Z.D., T.Z., and J.Y. draft the manuscript. All authors read and approved the final manuscript.

\section{FUNDING INFORMATION}

This study was supported by research grant 81560015 from the National Natural Science Foundation of China, and research grant 2017FE468(-210),2017FB468(-005) from Yunnan applied basic research projects-joint special project. 


\section{COMPLIANCE WITH ETHICAL STANDARDS}

Conflict of Interest. The authors declare that they have no conflict of interest.

Open Access This article is distributed under the terms of the Creative Commons Attribution 4.0 International License (http://creativecommons.org/licenses/by/4.0/), which permits unrestricted use, distribution, and reproduction in any medium, provided you give appropriate credit to the original author(s) and the source, provide a link to the Creative Commons license, and indicate if changes were made.

Publisher's Note Springer Nature remains neutral with regard to jurisdictional claims in published maps and institutional affiliations.

\section{REFERENCES}

1. Elenga, N., C. Merlin, R. le Guern, R. Kom-Tchameni, Y.M. Ducrot, M. Pradier, B. Ntab, K.A. Dinh-van, M. Sobesky, D. Mathieu, J.M. Dueymes, G. Egmann, H. Kallel, and M. Mathieu-Nolf. 2018. Clinical features and prognosis of paraquat poisoning in French Guiana: a review of 62 cases. Medicine (Baltimore) 97 (15): e9621.

2. Zyoud, S.H. 2018. Investigating global trends in paraquat intoxication research from 1962 to 2015 using bibliometric analysis. American Journal of Industrial Medicine 61 (6): 462-470.

3. Dusinska, M., et al. 1998. Responses of alveolar macrophages and epithelial type II cells to oxidative DNA damage caused by paraquat. Carcinogenesis 19 (5): 809-812.

4. S, N., and T. Shivanandappa. 2018. Neuroprotective action of 4hydroxyisophthalic acid against paraquat-induced motor impairment involves amelioration of mitochondrial damage and neurodegeneration in Drosophila. Neurotoxicology 66: 160-169.

5. Seo, H.J., S.J. Choi, and J.H. Lee. 2014. Paraquat induces apoptosis through cytochrome $\mathrm{C}$ release and ERK activation. Biomolecules \& Therapeutics (Seoul) 22 (6): 503-509.

6. Wang, Q., L. Yang, Y. Hua, S. Nair, X. Xu, and J. Ren. 2014. AMPactivated protein kinase deficiency rescues paraquat-induced cardiac contractile dysfunction through an autophagy-dependent mechanism. Toxicological Sciences 142 (1): 6-20.

7. Colle, D., M. Farina, S. Ceccatelli, and M. Raciti. 2018. Paraquat and maneb exposure alters rat neural stem cell proliferation by inducing ROS generation: new insights on pesticide-induced neurodevelopmental toxicity. Neurotoxicity Research 34: 820-833.

8. Possik, E., and A. Pause. 2015. Measuring ROS generation resistance of Caenorhabditis elegans in 96-well microtiter plates. Journal of Visualized Experiments 99: e52746.

9. Chang, X., W. Lu, T. Dou, X. Wang, D. Lou, X. Sun, and Z. Zhou. 2013. Paraquat inhibits cell viability via enhanced ROS generation and apoptosis in human neural progenitor cells. Chemico-Biological Interactions 206 (2): 248-255.
10. El-Boghdady, N.A., and N.F. Abdeltawab. 2017. Resveratrol and Montelukast alleviate paraquat-induced hepatic injury in mice: modulation of ROS generation, inflammation. Apoptosis 2017: 9396425.

11. Jaroonwitchawan, T., N. Chaicharoenaudomrung, J. Namkaew, and P. Noisa. 2017. Curcumin attenuates paraquat-induced cell death in human neuroblastoma cells through modulating ROS generation and autophagy. Neuroscience Letters 636: 40-47.

12. Filomeni, G., D. De Zio, and F. Cecconi. 2015. ROS generation and autophagy: the clash between damage and metabolic needs. Cell Death and Differentiation 22 (3): 377-388.

13. He, X., L. Wang, G. Szklarz, Y. Bi, and Q. Ma. 2012. Resveratrol inhibits paraquat-induced ROS generation and fibrogenic response by activating the nuclear factor erythroid 2-related factor 2 pathway. The Journal of Pharmacology and Experimental Therapeutics 342 (1): 81-90.

14. Amirshahrokhi, K. 2013. Anti-inflammatory effect of thalidomide in paraquat-induced pulmonary injury in mice. International Immunopharmacology 17 (2): 210-215.

15. Wang, H., L. Pan, L. Si, and J. Miao. 2018. The role of Nrf2-Keap1 signaling pathway in the antioxidant defense response induced by PAHs in the calm Ruditapes philippinarum. Fish \& Shellfish Immunology 80: 325-334.

16. Chen, B., Y. Lu, Y. Chen, and J. Cheng. 2015. The role of Nrf2 in ROS generation-induced endothelial injuries. The Journal of Endocrinology 225 (3): R83-R99.

17. Yu, M., H. Li, Q. Liu, F. Liu, L. Tang, C. Li, Y. Yuan, Y. Zhan, W. Xu, W. Li, H. Chen, C. Ge, J. Wang, and X. Yang. 2011. Nuclear factor p65 interacts with Keap1 to repress the Nrf2-ARE pathway. Cellular Signalling 23 (5): 883-892.

18. Verma, A.K., A. Yadav, J. Dewangan, S.V. Singh, M. Mishra, P.K. Singh, and S.K. Rath. 2015. Isoniazid prevents Nrf2 translocation by inhibiting ERK1 phosphorylation and induces ROS generation and apoptosis. Redox Biology 6: 80-92.

19. Qin, S., R.H. du, S.S. Yin, X.F. Liu, G.L. Xu, and W. Cao. 2015. Nrf2 is essential for the anti-inflammatory effect of carbon monoxide in LPSinduced inflammation. Inflammation Research 64 (7): 537-548.

20. Fan, H., H. Huang, L. Hu, W. Zhu, Y. Yu, J. Lou, L. Hu, and F. Chen. 2018. The activation of STIM1 mediates S-phase arrest and cell death in paraquat induced acute lung intoxication. Toxicology Letters 292: 123-135.

21. Martinez-Perez, D.A., M. Jimenez-Del-Rio, and C. Velez-Pardo. 2018. Correction to: Epigallocatechin-3-gallate protects and prevents paraquat-induced oxidative stress and neurodegeneration in knockdown dj-1-beta Drosophila melanogaster. Neurotoxicity Research 34 (3): 417.

22. Hanus, J., H. Zhang, Z. Wang, Q. Liu, Q. Zhou, and S. Wang. 2013. Induction of necrotic cell death by ROS generation in retinal pigment epithelial cells. Cell Death \& Disease 4: e965.

23. Tan, V.P., and S. Miyamoto. 2015. HK2/hexokinase-II integrates glycolysis and autophagy to confer cellular protection. Autophagy 11 (6): 963-964.

24. Fulda, S., and D. Kogel. 2015. Cell death by autophagy: emerging molecular mechanisms and implications for cancer therapy. Oncogene 34 (40): 5105-5113.

25. Hussong, M., S.T. Börno, M. Kerick, A. Wunderlich, A. Franz, H. Sültmann, B. Timmermann, H. Lehrach, M. Hirsch-Kauffmann, and M.R. Schweiger. 2014. The bromodomain protein BRD4 regulates the KEAP1/NRF2-dependent ROS generation response. Cell Death \& Disease 5: e1195.

26. Ge, W., H.L. Wang, and R.P. Sun. 2014. Clinical characteristics of paraquat poisoning in 22 Chinese children. Indian Journal of Pediatrics 81 (7): 670-674.

27. Yang, W., W. Liu, W. Yu, D. Fei, X. Meng, S. Yang, S. Meng, and M. Zhao. 2018. Angpt12 deficiency attenuates paraquat (PQ)- 
induced lung injury in mice by altering inflammation, oxidative stress and fibrosis through NF-kappaB pathway. Biochemical and Biophysical Research Communications 503 (1): 94-101.

28. Hirayama, N., T. Aki, T. Funakoshi, K. Noritake, K. Unuma, and K. Uemura. 2018. Necrosis in human neuronal cells exposed to paraquat. The Journal of Toxicological Sciences 43 (3): 193-202.

29. Li, H., et al. 2014. The effect of selective phosphatase inhibitors Salubrinal on autophagy and apoptosis in the lung tissue of rats with acute paraquat poisoning. Zhonghua Wei Zhong Bing Ji Jiu Yi Xue 26 (9): 671-675.

30. Ishola, I.O., A.A. Akinyede, T.P. Adeluwa, and C. Micah. 2018. Novel action of vinpocetine in the prevention of paraquat-induced parkinsonism in mice: involvement of ROS generation and neuroinflammation. Metabolic Brain Disease 33: 1493-1500.
31. Chen, J.W., B.B. Ni, B. Li, Y.H. Yang, S.D. Jiang, and L.S. Jiang. 2014. The responses of autophagy and apoptosis to ROS generation in nucleus pulposus cells: implications for disc degeneration. Cellular Physiology and Biochemistry 34 (4): $1175-1189$.

32. Hsu, H.C., C.Y. Chen, C.H. Chiang, and M.F. Chen. 2014. Eicosapentaenoic acid attenuated ROS generation-induced cardiomyoblast apoptosis by activating adaptive autophagy. European Journal of Nutrition 53 (2): 541-547.

33. Zhang, D., L. Ren, G.Q. Chen, J. Zhang, B.M. Reed, and X.H. Shen. 2015. ROS-induced ROS generation and apoptosis-like event directly affect the cell viability of cryopreserved embryogenic callus in Agapanthus praecox. Plant Cell Reports 34 (9): 1499-1513. 